\title{
The Relationship Between Serum Lead Level and Uremic Pruritus in End-Stage Renal Disease Patients on Regular Hemodialysis
}

Essam Eldin Mahmoud Lotfy ${ }^{1}$, Lamiaa Abd Elwahab Mohammed ${ }^{2}$, Nafesa Mohammed Kamal $^{1}$, Hatem Elmaghawry Mohammed Elsheikh*1

Departments of ${ }^{1}$ Internal Medicine \& Nephrology and ${ }^{2}$ Clinical Pathology, Faculty of Medicine, Zagazig

University, Sharkia, Egypt

*Corresponding Author: Hatem Elmaghawry Mohammed Elsheikh, Mobile: (+20)01558857795,

Email: hatemelshiekh@gmail.com

\begin{abstract}
Background: Uremic pruritus (UP) is commonly described as a daily or near-daily occurrence of itch that spans large bilaterally symmetrical surface areas. Blood lead level (BLL) has been noted to be associated with inflammation and nutritional status in long-term HD patients.

Objective: To evaluate the possible relationship between BLL and UP in chronic HD patients.

Patients and Methods: This Cross-Sectional Study was carried out in the Hemodialysis Unit in EL Agouza Hospital from November 2018 to the end of April 2019 and included 100 randomly selected patients with endstage who received hemodialysis sessions thrice weekly, four hours /session, for more than 6 months. Dialysate with standard ionic composition and a bicarbonate-based buffer is used for all patients.

Results: The mean age of the chosen patients were \pm SD $48.6 \pm 7.1$ years and the difference among the groups was non-significant (p-value 0.116). The study included 42 females (42\%) and 58 males (58\%). There was no significant difference among the studied groups $(\mathrm{p}=0.292)$ regarding sex. According to Pruritus Onset in our study, there was a non-statistically significant difference among the studied groups. In our study, there was a statistically highly significant difference among different groups regarding Serum Lead ( $\mu \mathrm{g} / \mathrm{dL}$ ) (p-value $<0.001)$. In our study, Serum Lead $\geq 14 \mu \mathrm{g} / \mathrm{dL}$ is a cut-off value predictor for pruritus in HD patients with a sensitivity of $89.5 \%$, specificity of $64.2 \%$, and an accuracy of $69 \%$.
\end{abstract}

Conclusion: Serum Lead is a predictor for the incidence of pruritus in patients with end-stage renal disease maintained on hemodialysis.

Keywords: Uremic pruritus, Blood lead level, End-Stage Renal Disease.

\section{INTRODUCTION}

Uremic pruritus is most commonly described as a daily or near-daily occurrence of itch that spans large bilaterally symmetrical surface areas (1). It is a common and burdensome symptom for patients with kidney failure, affecting up to $46 \%$ of hemodialysis patients ${ }^{(2)}$. The association between uremia and pruritus was first reported more than a century ago ${ }^{(3)}$.

Patients with severe chronic renal failure may be predisposed to the development of xerosis, hyperpigmentation, uremic roseola, calcinosis cutis, acquired perforating dermatosis, bullous dermatosis of hemodialysis, and pruritus (4). Although uremic pruritus (UP) is a common and annoying symptom for end-stage renal disease patients on hemodialysis (HD) and peritoneal dialysis, its pathogenesis is poorly understood $^{(5)}$.

Blood lead level (BLL) has been noted to be associated with inflammation and nutritional status in long-term HD patients ${ }^{\left({ }^{(}\right)}$. BLLs in HD patients might increase the intensity of or have an addictive role of pruritus caused by other more common risk factors ${ }^{(7)}$.

This study aims to evaluate the possible relationship between BLL and UP in chronic HD patients.

\section{PATIENTS AND METHODS}

Our study was conducted on ESRD patients in the hemodialysis unit at Alagouza hospital in Giza during the period from November 2018 to the end of April 2019 (six months period).
Type of study: Cross-sectional Study
Inclusion criteria: Patients age between 16 to 60 years old. Patients maintained on Hemodialysis for at least 6 months were recruited in this study. Patients receive hemodialysis sessions thrice weekly, four hours for each session, Dialysate with standard ionic composition and the bicarbonate-based buffer is used for all patients, with a low flux polysulphone dialyzer F10. The blood flow was usually kept between 250 300 and the dialysate flow were $500 \mathrm{ml} / \mathrm{min}$. Ultrafiltration was controlled volumetrically in all hemodialysis machines used in this study. One hundred patients met the inclusion criteria out of 120 patients.
Exclusion criteria: Any associated primary skin lesion. Patients age above 60 years old or less than 16 years old. Patients with malignancies, infectious diseases, pregnancy, and immune diseases. Those who had been admitted or received surgery within 3 months of the study. Patients who work as a painter or in 
battery factories. Patients with cholestasis. Patients who refused to participate in the study.

\section{Ethical Considerations}

Approval was obtained from Zagazig University Institutional Review Board (IRB) ethical committee.

Informed written consent was obtained from all participants in this research after the explanation of the benefits and possible risks of the study. Privacy of all patients' data was guaranteed by a special code number for every patient' file that includes all investigations

Study population: 100 out of 120 patients met the inclusion criteria. They were included in a comprehensive sample. Our 100 patients were Endstage renal disease (58\% males and $42 \%$ females), their age ranged between 28 years to 60 years with a median age of 49 .

\section{Study patients divided into three groups:}

- Group I: low blood lead level $(<15 \mu \mathrm{g} / \mathrm{dL})$ included 56 patients, 4 patients of them with uremic pruritus, with median age 50 .

- Group II: High normal blood lead level (15 $\leq$ BLL $<25 \mu \mathrm{g} / \mathrm{dL}$ ) included 32 patients, 8 patients of them with uremic pruritus, with median age 49.

- Group III: Abnormal high blood lead level ( $\geq 25$ $\mu \mathrm{g} / \mathrm{dL}$ ) included 12 patients, 7 patients of them with uremic pruritus, with median age 44 .

\section{All patients were subjected to the following:}

History: Personal history: name, age, sex, and History of pruritus.

\section{Laboratory investigation.}

Serum Lead level: measured by using Flame Atomic Absorption Spectrophotometry (model M6). Blood sample was taken on heparin, and then the RBCs are hemolyzed using nitric acid to extract lead. Two standard solutions are prepared, a curve is drawn between three points of measurements of blank mineral water, and the two standards are settled.
Samples are plotted on this curve and results are obtained.

\section{Statistical Analysis}

Data were analyzed using Statistical Program for Social Science (SPSS) version 25.0 for windows (SPSS Inc., Chicago, IL, USA), NCSS 12 for windows (NCSS LCC., Kaysville, UT, USA). Quantitative data were expressed as mean \pm standard deviation (SD). Median and inter-quartile range (IQR) were also calculated for quantitative data. Qualitative data were expressed as frequency and percentage. The following tests were done: A one-way analysis of variance (ANOVA). Kruskal-Wallis test. Chi-square (X2) test. Receiver operating characteristic (ROC) curve analysis. P-value was set at $<0.05$ for significant results.

\section{RESULTS}

Our study included 100 patients with end-stage renal disease (55\% males and $42 \%$ females), their age ranged between 28 years to 60 years with a median age of 49 .

\section{Study patients divided into three groups:}

$>$ Group I: low blood lead level $(<15 \mu \mathrm{g} / \mathrm{dL})$ included 56 patients, 4 patients of them with uremic pruritus, with median age 50 .

> Group II: High normal blood lead level $(15 \leq$ BLL $<25 \mu \mathrm{g} / \mathrm{dL}$ ) included 32 patients, 8 patients of them with uremic pruritus, with median age 49 .

> Group III: Abnormal high blood lead level $(\geq 25$ $\mu \mathrm{g} / \mathrm{dL}$ ) included 12 patients, 7 patients of them with uremic pruritus, with median age 44 .

\section{Demographic data of the studied groups:}

According to sex, our study included 100 patients 42 (42\%) female, and 58 (58\%) male. There was no significant difference between studied groups $(\mathrm{p}=0.292)$ regarding sex.

According to age in our study conducted on 100 patients with mean age \pm SD $48.6 \pm 7$.1years. The difference between the groups was non-significant ( $p$ value 0.116 ).

Table (1): Demographic data of the whole study population

\begin{tabular}{|l|c|}
\hline \multicolumn{1}{|c|}{ Demographic data } & All patients \\
\hline Count (\%) & $\mathbf{1 0 0 ( 1 0 0 \% )}$ \\
\hline Gender & $58(58 \%)$ \\
\hline Male & $42(42 \%)$ \\
\hline Female & $48.6 \pm 7.1$ \\
\hline Age (years) & $49(44-55)$ \\
\hline Mean \pm SD &
\end{tabular}


Table (2): Comparison among the studied groups regarding the demographic data.

\begin{tabular}{|c|c|c|c|c|c|}
\hline Demographic data & Low normal BLL & High normal BLL & High BLL & \multirow{2}{*}{ Test } & \multirow{2}{*}{$\begin{array}{c}\text { P-value } \\
\text { (Sig.) }\end{array}$} \\
\hline Count & 56 & 32 & 12 & & \\
\hline \multicolumn{6}{|l|}{ Gender } \\
\hline Male & $35(62.5 \%)$ & $15(46.9 \%)$ & $8(66.7 \%)$ & \multirow{2}{*}{$2.461 \%$} & 0.292 \\
\hline Female & $21(37.5 \%)$ & $17(53.1 \%)$ & $4(33.3 \%)$ & & (NS) \\
\hline \multicolumn{6}{|l|}{ Age (years) } \\
\hline Median (IQR) & $50(43.25-54)$ & $49(48-55)$ & $44(40-53.75)$ & $4.307^{\mathrm{K}}$ & $0.116(\mathrm{NS})$ \\
\hline
\end{tabular}

Incidence of pruritus and its description:

According to pruritus onset in our study, there was a non-statistically significant difference between the studied groups.

Table (3): Incidence of pruritus and its description

\begin{tabular}{||l|c|}
\hline \multicolumn{1}{|c|}{ Pruritus and description } & All patients $(\mathbf{N}=19)$ \\
\hline Count $(\%)$ & $100(100 \%)$ \\
\hline \hline Pruritus & \\
\hline No & $81(81 \%)$ \\
\hline Yes & $19(19 \%)$ \\
\hline
\end{tabular}

Table (4): Serum lead of all the studied groups

\begin{tabular}{|c|c|}
\hline Serum Lead & All patients \\
\hline Count (\%) & $100(100 \%)$ \\
\hline Serum Lead $(\mu \mathrm{g} / \mathrm{dL})$ & $N=<25$ \\
\hline Mean \pm SD & $15.3 \pm 7.3$ \\
\hline Median (IQR) & $12(9-21)$ \\
\hline
\end{tabular}

In our study, there was a statistically highly significant difference among different studied groups regarding Serum Lead $(\mu \mathrm{g} / \mathrm{dL})(\mathrm{p}$-value $<0.001)$.

Table (5): Comparison between the studied groups regarding serum lead

\begin{tabular}{|c|c|c|c|c|c|}
\hline & $\begin{array}{c}\text { Low normal BLL } \\
\text { group }\end{array}$ & $\begin{array}{c}\text { High normal BLL } \\
\text { group }\end{array}$ & High BLL group & \multirow[t]{2}{*}{ Test } & \multirow{2}{*}{$\begin{array}{l}\text { P-value } \\
\text { (Sig.) }\end{array}$} \\
\hline Count & 56 & 32 & 12 & & \\
\hline \multicolumn{6}{|c|}{ Serum Lead $(\mu \mathrm{g} / \mathbf{d L})$} \\
\hline $\begin{array}{l}\text { Median } \\
(\mathrm{IQR})\end{array}$ & $\begin{array}{c}9.5 \\
(8.25-12)\end{array}$ & $\begin{array}{c}20.5 \\
(15.75-23)\end{array}$ & $\begin{array}{c}29 \\
(27.25-30)\end{array}$ & $78.031^{\mathrm{K}}$ & $<0.001(\mathrm{HS})$ \\
\hline
\end{tabular}

Kruskal Wallis test. $\mathrm{P}<0.05$ is significant. Sig.: significance.



Figure (1): Comparison between the studied groups regarding serum Lead level 


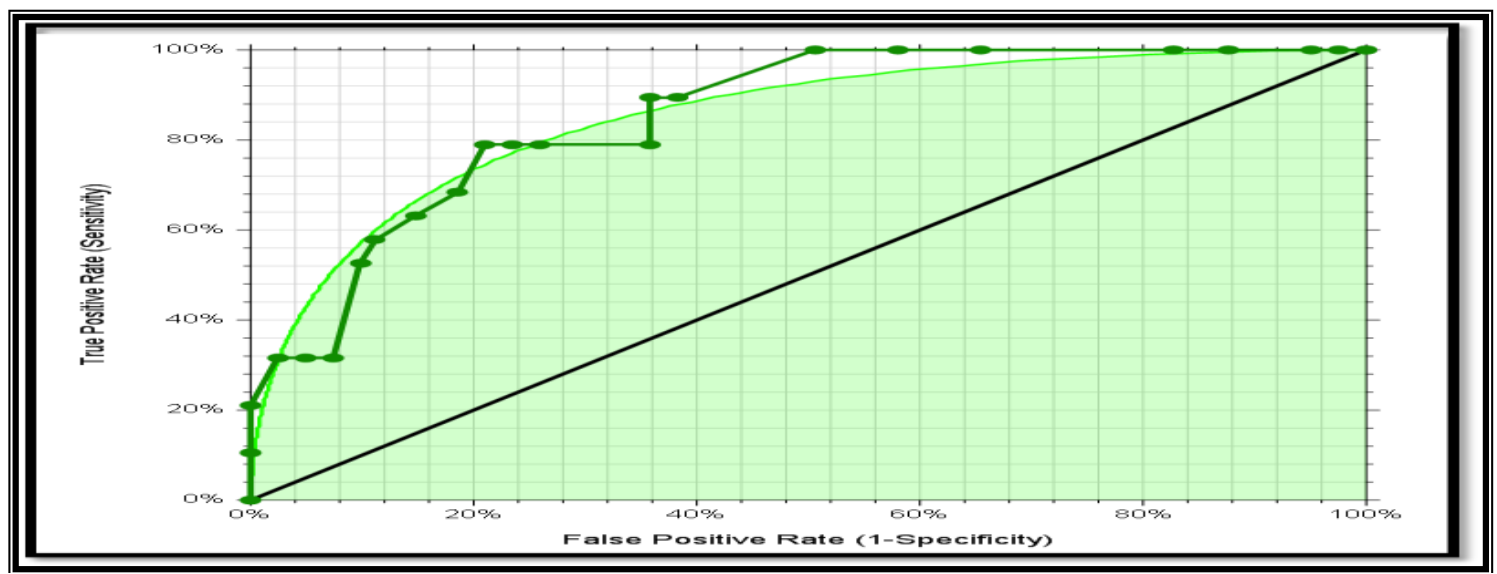

Figure (2): ROC curve analysis for Serum Lead $(\mu \mathrm{g} / \mathrm{dL})$ in predicting pruritus

Table (6): The predictive performance of serum lead ( $\mu \mathrm{g} / \mathrm{dL})$ for pruritus; ROC curve analysis

\begin{tabular}{|c|c|c|c|c|c|c|c|}
\hline $\begin{array}{c}\text { Cut-off } \\
\text { value }\end{array}$ & $\begin{array}{c}\text { SN \% } \\
(\mathbf{9 5 \%} \text { CI })\end{array}$ & $\begin{array}{c}\text { SP \% } \\
(\mathbf{9 5 \%} \text { CI })\end{array}$ & $\begin{array}{c}\text { PPV \% } \\
(\mathbf{9 5 \%} \text { CI })\end{array}$ & $\begin{array}{c}\text { NPV \% } \\
(\mathbf{9 5 \%} \text { CI })\end{array}$ & $\begin{array}{c}\text { Accuracy \% } \\
(\mathbf{9 5 \%} \text { CI })\end{array}$ & $\begin{array}{c}\text { AUROC } \\
(\mathbf{9 5 \%} \text { CI })\end{array}$ & $\begin{array}{c}\text { P-value } \\
(\text { Sig. })\end{array}$ \\
\hline S. Lead & $\mathbf{8 9 . 5 \%}$ & $\mathbf{6 4 . 2 \%}$ & $\mathbf{3 7 \%}$ & $\mathbf{9 6 . 3 \%}$ & $\mathbf{6 9 \%}$ & $\mathbf{0 . 8 5 4}$ & $<\mathbf{0 . 0 0 1}$ \\
$\geq 14 \mu \mathrm{g} / \mathrm{dL}$ & $\mathbf{6 6 . 9}-\mathbf{9 8 . 7})$ & $\mathbf{5 2 . 8}-\mathbf{7 4 . 6})$ & $\mathbf{2 3 . 2}-\mathbf{5 2 . 5})$ & $\mathbf{8 7 . 3 - 9 9 . 6 )}$ & $(\mathbf{5 9 - 7 7 . 9 )}$ & $(\mathbf{0 . 7 4 7 - 0 . 9 1 8 )}$ & $($ HS $)$ \\
\hline
\end{tabular}

ROC curve: Receiver Operating Characteristic curve.

SN: Sensitivity. SP: Specificity. PPV: Positive Predictive Value. NPV: Negative Predictive Value.

AUROC: Area Under Receiver Operating Characteristic curve.

95\%CI: 95\% Confidence Interval. $p<0.05$ is significant. Sig.: significance.

In our study, serum lead level $\geq 14 \mu \mathrm{g} / \mathrm{dL}$ is a cut-off value predictor for pruritus in HD patients with a sensitivity of $89.5 \%$, a specificity of $64.2 \%$, and an accuracy of $69 \%$.

\section{DISCUSSION}

According to age in our study conducted on 100 patients with mean age \pm SD $48.6 \pm 7.1$ years.

The difference among the groups was nonsignificant (p-value 0.116 ) regarding age.

Contradictory with our result, Muntner et al. ${ }^{(8)}$ who studied Blood lead and chronic kidney disease in the general population found that there was a highly statistically significant difference regarding Age $(\mathrm{p}$ $<0.001)$.

This discrepancy between the previous study and our results regarding age is due to the older age of previous study populations range from 40 to more than 75 years old.

According to sex, our study included 100 patients 42 (42\%) females, and 58 (58\%) males. There was no significant difference among studied groups $(\mathrm{p}=0.292)$ regarding sex.

In agreement with our study, Lin et al. (9) included 211 patients with diabetes on long-term HD therapy at 3 centers and found that there was a statistically non-significant difference regarding sex with $\mathrm{p}$ value $=0.4$.

According to pruritus onset in our study, there was a non-statistically significant difference among the studied groups.

Contradictory with our result, Dyachenko et al. (10) who studied Hemodialysis related pruritus and associated cutaneous manifestations and found that there was a statistically significant difference regarding Pruritus Onset,.

In our study, there was a statistically highly significant difference among different groups regarding Serum Lead $(\mu \mathrm{g} / \mathrm{dL})$ ( $\mathrm{p}$-value $<0.001)$.

This was concordant with Weng $\boldsymbol{e t}$ al. ${ }^{(7)}$ study in which 866 patients on regular dialysis were divided according to BLL and the difference among the groups was highly significant regarding serum PTH $(\mathrm{pg} / \mathrm{mL})$ and Serum Lead $(\mu \mathrm{g} / \mathrm{dL})$ (p-value $<0.001)$.

In our study, serum lead $\geq 14 \mu \mathrm{g} / \mathrm{dL}$ is a cut-off value predictor for pruritus in HD patients with a sensitivity of $89.5 \%$, a specificity of $64.2 \%$, and an accuracy of $69 \%$.

\section{CONCLUSION}

Serum lead is a predictor for the incidence of pruritus in patients with end-stage renal disease maintained on hemodialysis.

\section{REFERENCES}

1. Simonsen E, Komenda P, Lerner B et al. (2017): Treatment of uremic pruritus: a systemic review. Am J Kidney Dis., 70(5):638-655.

2. Davison S, Levin A, Moss A et al. (2015): Executive summary of the KDIGO Controversies Conference on Supportive Care in Chronic Kidney Disease: developing a roadmap to improving quality care. Kidney International, 88: 447-459. 
3. Almeras C, Argiles À (2009): Progress in uremic toxin research: the general picture of uremia. Seminars in dialysis. Wiley Online Library, 15: 329-333.

4. Levillard D, Kambil S (2015): Cutaneous Manifestations IN Chronic Renal Disease-An observational study of skin changes, new findings, their association with hemodialysis, and their correlation with the severity of CKD. International Journal of Scientific and Research Publications, 5: 2250-3153.

5. Patel T, Freedman B, Yosipovitch G (2007): An update on pruritus associated with CKD. Am J Kid Dis., 50(1): 11-20.

6. Szeto C, Kwan B, Chow, Lai K, et al. (2008): Endotoxemia is related to systemic inflammation and atherosclerosis in peritoneal dialysis patients. Clinical Journal of the American Society of Nephrology, 3: 431436.
7. Weng C, Hsu C, Hu C (2017): Blood lead level is a positive predictor of uremic pruritus in patients undergoing hemodialysis. Ther Clin Risk Manag., 13:717-723.

8. Muntner P, He J, Vupputuri S et al. (2003): Blood lead and chronic kidney disease in the general United States population: results from NHANES III. Kidney International, 63: 1044-1050.

9. Lin H, Liu Y, Liu J et al. (2008): Uremic pruritus, cytokines, and polymethylmethacrylate artificial kidney. Artif Organs, 32(6): 468-472.

10. Dyachenko P, Shustak A, Rozenman D. (2006): Hemodialysis related pruritus and associated cutaneous manifestations. International Journal of Dermatology, 45: 664-667. 